\title{
Secular reduction of excess mortality in hip fracture patients $>85$ years
}

Trine E Finnes ${ }^{1,2^{*}}$, Haakon E Meyer ${ }^{3,4}$, Jan A Falch ${ }^{3}$, Asle W Medhus ${ }^{5}$, Tore Wentzel-Larsen ${ }^{6,7,8}$ and Cathrine M Lofthus ${ }^{2,5}$

\begin{abstract}
Background: More than 20\% of the hip fracture patients die within the first year after the incident. Few data are available on the trends in mortality following a hip fracture. The present aim was to study changes in excess mortality after hip fracture from 1978/79 up to 1996/97.

Methods: Data on 5180 hip fracture patients aged $\geq 50$ years, identified in three earlier, well validated, incidence studies from Oslo were used. The studies took place in the two years periods 1978-79 and 1989-89 and in a one year period from 1st of May 1996 to 30th of April 1997. The study was designed as a historic cohort study. Exposure was sustaining a hip fracture in the registration periods. Outcome was death of all causes. Age- and sex-specific one year-mortality rates were provided by Statistics Norway. Standardized mortality ratios (SMR) were calculated for the three cohorts for each sex and age-group, for the 0-6 months, 6-12 months, 0-1 year, 1-5 years and 5-10 years intervals after fracture. To assess the duration of the excess mortality in hip fracture patients, time-framed Kaplan-Meier curves for consecutive 5-years intervals were conducted for the hip fracture patients and the corresponding background population. Only patients still alive at the start of the time interval were included. One sample log rank tests were used to test for statistical significance.
\end{abstract}

Results: The one-year SMR ranged from 3.64 (2.82 - 4.61) to 4.53 (3.67 - 5.54) in men and from 2.78 (2.39 - 3.19) to 3.60 (3.19 - 4.05) in women. In the 0-6 months interval a reduction in SMR from 1978/79 to 1996/97 was observed in women aged $\geq 85$ years. The duration of excess mortality ranged from two years in men $\geq 85$ years to more than ten years in men and women aged 65-84 years.

Conclusion: Excess mortality among hip fracture patients remains high. Over the decades, a reduced excess mortality was mainly seen in the oldest patients, suggesting that specific efforts intending to improve prevention and treatment of osteoporosis and osteoporotic fractures in the youngest elderly are required.

\section{Background}

Hip fractures are associated with high morbidity and mortality [1-3]. Most studies over the last five decades report a one-year mortality ranging from $15-30 \%$ [4-9], and the mortality tends to be higher in men than in women $[8,10]$. The highest mortality is observed within the first 6 months after the fracture and declines thereafter $[5,6,10]$.

Whereas the relative excess mortality in hip fracture patients is highest among the youngest, the absolute

\footnotetext{
*Correspondence: trine_finnes@yahoo.com

'Department of Internal Medicine, Innlandet Hospital Trust, Skolegata 32, Hamar N-2318, Norway

${ }^{2}$ Faculty of Medicine, University of Oslo, Klaus Torgårds vei 3, Oslo N-0372, Norway

Full list of author information is available at the end of the article
}

excess mortality is highest among the oldest [5]. The excess mortality is associated with both pre-existing comorbidity and fracture related complications e.g. infections and delirium $[1,6,11,12]$. Few studies on secular trends and changes in excess mortality after hip fractures over a prolonged period are available and the results are conflicting $[5,8,9,11,13]$. In addition, the duration of the period with excess mortality is uncertain $[9,11,13]$.

Oslo, the capital of Norway, has the highest reported incidence of hip fracture world-wide [14]. The incidence has been reported every decade since the 1970'ies [14-16]. However, reports on mortality after hip fractures for this area are limited [6]. The present aim was to study secular trends in excess mortality after hip fracture in Oslo in the period of 1978-1997.

\section{Biomed Central}




\section{Methods}

\section{Study population}

Data from three earlier incidence studies on hip fracture in Oslo were used [14-16]. These studies include all patients $\geq 20$ years with hip fracture in the two-year periods 1978 to $1979 \quad(\mathrm{n}=2067)$ and 1988 to1989 $(n=2697)$, and in the one-year period from 1st of May 1996 until 30th of April 1997 ( $n=1290)$. Hip fractures (International Classification of Diseases, ninth revision (ICD-9) code 820.X) were identified through diagnosis registers, operating theatres protocols, medical records, and $\mathrm{x}$-ray records. Fractures in patients residing outside Oslo or fractures due to malignancy were not included in these studies.

Hip fractures in patients aged $<50$ years are infrequent, and the younger hip fracture patients differ considerably from the older hip fracture patients regarding comorbidity $[17,18]$. For this reason, patients aged $<50$ years were not included in the current study. For patients with more than one fracture in any of the inclusion periods, the first fracture was included in the present study.

Registration cards from the incidence studies of 1978/ 79 and 1988/89 were retrieved, and the cases were identified through name and date of birth. The data from the registration cards were transferred into an electronic register, and linked to the National Population Register (Norwegian Tax Administration, Oslo) to achieve the full unique Norwegian 11-digit identification number for each patient. The data from 1996/97 were stored in an electronic register with the 11-digit identification number.

In the $1978 / 79$-cohort, 50 patients were aged $<50$ years. Of the patients aged $\geq 50$ years, 80 patients were not included due to: I) unidentifiable date of fracture $(n=53)$; II) loss to follow up $(\mathrm{n}=1)$; III) missing unique identification number $(\mathrm{n}=24)$; IV) fracture due to metastasis $(n=1) ; V)$ double registration $(n=1)$. There were no differences regarding sex, age, and type of fracture when comparing the excluded patients with the included patients (Chi-square test and Student's $t$ test).
In the 1988/89-cohort, 26 patients who had sustained a hip fracture in the previous inclusion period and 42 patients aged $<50$ years were not included. In addition, ten patients were not included due to: I) unidentifiable date of fracture $(n=2)$; II) loss to follow up $(n=4)$; III) missing unique identification number $(n=3)$; IV) resident outside Oslo $(\mathrm{n}=1)$.

In the $1996 / 97$ cohort, 15 patients had sustained a hip fracture in one of the earlier inclusion periods, and 21 patients were aged $<50$ years. All the remaining patients were included.

Data from the 5180 cases included (Table 1) were linked to The Cause of Death Register provided by Statistics Norway (Statistics Norway, Kongsvinger, Norway). The patients were followed up with respect to death from all causes until 31st of December 2007 (Additional file 1: Flow chart).

\section{Study design}

The study was designed as a historic cohort study. Exposure was sustaining a hip fracture in the registration periods. Outcome was death from all causes. Covariates were sex, age, and type of fracture.

\section{Data and definitions}

The hip fractures were defined as femoral neck or intertrochanteric. Subtrochanteric fractures were not included.

Hip fractures in patients aged $\geq 65$ years are often referred to as geriatric hip fractures, and younger patient are frequently not included in survival studies $[8,13]$. Those aged $\geq 85$ years have a high absolute mortality during the first six months of follow up, and a shorter duration of excess mortality than younger hip fracture patients $[5,7,9]$. The patients were therefore divided into following age groups: I) 50-64 years; II) 65-84 years; and III) $\geq 85$ years.

In the 1978/79-cohort, fracture time was only registered by month and year. Date of fracture was consequently set to the first of the month to avoid negative

Table 1 Characteristics of the included patients of the different cohorts

\begin{tabular}{|c|c|c|c|c|}
\hline & $1978 / 79$ & $1988 / 89$ & $1996 / 97$ & p-value* \\
\hline Included, n & 1937 & 2619 & 1254 & \\
\hline Men, n (\%) & $215(21.5)$ & $546(20.8)$ & $279(22.2)$ & 0.597 \\
\hline Mean age at time of fracture, men ( $95 \% \mathrm{Cl})$ & $74.2(73.3-75.2)$ & $76.6(75.9-77.4)$ & $79.5(78.4-80.6)$ & $<0.001$ \\
\hline Mean age at time of fracture, women $(95 \% \mathrm{Cl})$ & $76.8(76.4-77.3)$ & $80.2(79.8-80.6)$ & $81.4(80.9-82.0)$ & $<0.001$ \\
\hline 50-64 years, $n(\%)$ & $254(13.1)$ & $170(6.5)$ & $60(4.8)$ & \\
\hline 65-84 years, $n(\%)$ & $1322(68.2)$ & $1606(61.3)$ & $719(57.3)$ & \\
\hline$\geq 85$ years, $n(\%)$ & $361(18.6)$ & $843(32.2)$ & $475(37.9)$ & \\
\hline Intertrochanteric fractures, n (\%) & $751(38.8)$ & $1085(41.4)$ & $563(44.9)$ & 0.003 \\
\hline Median follow up time, years (range) & $4.9(0-30.0)$ & $3.37(0-20.0)$ & $3.63(0-11.7)$ & \\
\hline
\end{tabular}

* $p$-value for differences between the cohorts. 
survival time. To assess the influence of this fictive fracture date, survival analyses with the fracture date set to both the 1 st and the 15th of the month were performed. The different fictive fracture days did not influence the results presented.

\section{Statistical analyses}

Comparisons of baseline data between the three cohorts were made using the Kruskal Wallis test and the One-Way -ANOVA. Kaplan-Meier-curves were estimated for each cohort stratified by sex, age group, and fracture type.

Age- and sex-specific one year-mortality rates for Oslo from 1978-2007 were provided by Statistics Norway and were used to calculate the expected survival curves for each cohort (Figure 1) as described by Therneau [19].

Standardized mortality ratio (SMR) expresses the level of excess mortality [20], and was calculated as the ratio of patient mortality to mortality in the background population of Oslo. The background population corresponded to the study population with respect to time period, sex, and year of birth. SMRs were calculated for the three cohorts for each sex, age-group, and fracture type, for the 0-6 months, 6-12 months, 0-1 year, $1-5$ years and 5-10 years intervals after fracture. Sex- and age stratified analyses were also performed for the $0-1$ year interval to allow comparison with earlier studies. Confidence intervals for SMR were computed as bootstrap $\mathrm{BC}_{\mathrm{a}}$ intervals with 10000 replications [21].

To assess the duration of the excess mortality, timeframed Kaplan-Meier curves for 5-years intervals starting at each year of the follow up time were calculated for each sex and age-group. These curves were compared with the corresponding expected survival curves. Only patients still alive at the start of the time interval were included. One sample log rank tests were used to test for statistical significance between observed and expected curves. The beginning of the last 5 year interval, where there still was statistical significance between the expected and observed curves, was set as duration of excess mortality.

The level of statistical significance was set at $\mathrm{p}<0.05$. Analyses were performed using SPSS 14.0 (SPSS Inc., Chicago, IL, USA) and R 2.10.1 (The R Foundation for Statistical Computing, Vienna, Austria) with the R packages survival and boot.

\section{Ethics and approvals}

The study is performed in compliance with the Helsinki Declaration. The Regional Committee for Research Ethics approved the study. A dispensation from professional secrecy was given by the Norwegian Directorate for Health and Social Affairs. Permission to handle sensitive information were sought and received from the Data Protection Agency.

\section{Results}

\section{Patient characteristics}

The proportion of men was $21-22 \%$ in all three cohorts (Table 1). Mean age at time of fracture increased by about 5 years in both men and women from 1978/79 to 1996/ 97. The proportion of patients aged $\geq 85$ years increased from 19 to $38 \%$. The proportion of intertrochanteric fractures was higher in the 1996/97-cohort than in the 1978/79-cohort $(\mathrm{p}=0.003)$.

\section{Excess mortality within each cohort}

Kaplan-Meier curves of the three cohorts showed a substantially higher mortality for both sexes, in all age groups, than did the expected survival curves (Figure 1).

One-year mortality in the different cohorts ranged from $30 \%$ to $33 \%$ in men, and from $21 \%$ to $25 \%$ in women (data not shown).

The highest SMR was observed within 6 months after the fracture (Tables 2, 3, 4).

Men had higher SMR than women during all follow up intervals and in all three cohorts.

The SMRs were higher in those aged 65-84 years than in those aged $\geq 85$ years during all follow up intervals and in all three cohorts (Table 3). There were no substantial differences in SMRs of femoral neck and intertrochanteric fractures within the cohorts (Table 4). Sex stratified analyses for each age group demonstrated higher SMR in men than in women in patients aged 5684 and $\geq 85$ years (Table 5). The lowest SMR was seen in the oldest age group in both sexes.

\section{Secular changes in excess mortality from 1978 to 1997}

Changes in SMRs over the decades were more evident during the 0-6 month interval, than during long term follow up (Tables 2, 3, 4).

In women, there was a reduction in SMR from 1978/ 79 to $1996 / 97$ during the $0-6$ month interval. In men, a similar trend was observed (Table 2). In the age stratified analyses a statistically significant reduction in SMR from $1978 / 79$ to $1996 / 97$ was evident in the 0-6 months interval in those aged $\geq 85$ years (Table 3 ). Further ageand sex stratified analyses performed for the 0-1 year interval revealed a statistically significant reduction in SMR only in women aged $\geq 85$ years and a trend towards declining SMR in men aged 65-84 years (Table 5).

The changes in SMR from 1978/79 to $1996 / 97$ were similar for femoral neck and intertrochanteric fractures (Table 4). 


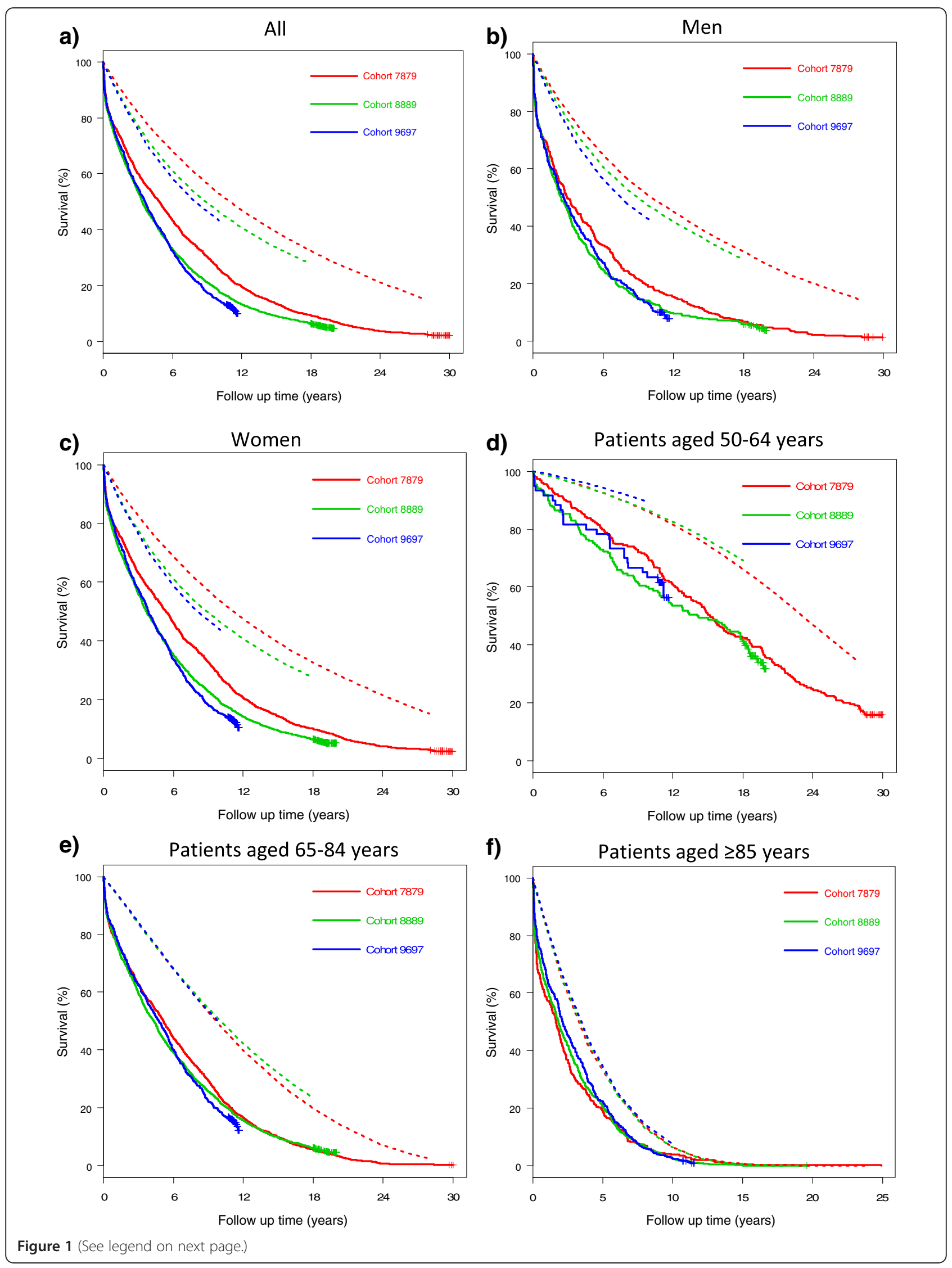


(See figure on previous page.)

Figure 1 Expected survival and observed survival by cohort. Expected survival (dotted curves) and observed survival (continuous curves) by cohort. a) All, b) Men, c) Women, d) Patients aged 50-64 years, e) Patients aged 65-84 years, and f) Patients aged $\geq 85$ years (Please note slight difference in the time scale). A substantially higher mortality in hip fracture patients, than in the corresponding background population, is shown. The better survival in the 1978-79 cohort in the analyses not stratified on age is explained by the younger patients in this cohort.

\section{Duration of excess mortality}

The longest duration of excess mortality was found in women aged 65-84 years (Table 6), where the excess mortality lasted more than 19 years in the 1978/79-cohort, for 14 years in the 1988/89-cohort, and until end of follow up in the 1996/97-cohort. The shortest period with excess mortality was seen in men aged $\geq 85$ years. In this age-group, the mortality returned to the level of the background population after two to four years. Except for women aged $\geq 85$ years, there was a trend towards shorter duration of excess mortality from $1978 / 79$ to $1996 / 97$.

\section{Discussion}

The present study demonstrates considerable excess mortality for a prolonged period after hip fracture. In the period from $1978 / 79$ to $1996 / 97$, excess mortality during the first six months after the fracture declined

Table 2 Standardized mortality rates in given time intervals with respect to sex and cohort

\begin{tabular}{|c|c|c|c|c|c|c|}
\hline Follow up time & Sex & Cohort & $\mathrm{n}$ & Dead, n (\%) & Expected dead, $\mathrm{n}$ & SMR (95\% Cl) \\
\hline & & $78 / 79$ & 417 & $105(25.2)$ & 15.41 & $6.81(4.47-8.35)$ \\
\hline & Men & $88 / 89$ & 546 & $137(25.1)$ & 22.96 & $5.97(4.90-7.13)$ \\
\hline & & $96 / 97$ & 279 & $72(25.8)$ & 14.00 & $5.14(3.90-6.61)$ \\
\hline \multicolumn{7}{|l|}{$0-6$ months } \\
\hline & \multirow{3}{*}{ Women } & $78 / 79$ & 1520 & $249(16.4)$ & 48.74 & $5.11(4.44-5.80)$ \\
\hline & & $88 / 89$ & 2073 & $371(17.9)$ & 89.67 & $4.14(3.68-4.61)$ \\
\hline & & $96 / 97$ & 975 & $156(16.0)$ & 43.36 & $3.60(2.99-4.26)$ \\
\hline \multirow{6}{*}{ 6-12 months } & \multirow{3}{*}{ Men } & $78 / 79$ & 312 & $21(6.7)$ & 12.41 & $1.69(1.02-2.48)$ \\
\hline & & $88 / 89$ & 409 & $38(9.3)$ & 18.80 & $2.02(1.38-2.70)$ \\
\hline & & $96 / 97$ & 207 & $19(9.2)$ & 11.03 & $1.72(1.00-2.59)$ \\
\hline & \multirow{3}{*}{ Women } & $78 / 79$ & 1271 & $76(6.0)$ & 41.45 & $1.83(1.42-2.28)$ \\
\hline & & $88 / 89$ & 1702 & $148(8.7)$ & 75.42 & $1.96(1.65-2.30)$ \\
\hline & & $96 / 97$ & 819 & $70(8.5)$ & 38.19 & $1.83(1.42-2.29)$ \\
\hline \multirow{6}{*}{$1-5$ years } & \multirow{3}{*}{ Men } & $78 / 79$ & 291 & $129(44.3)$ & 71.90 & $1.79(1.47-2.18)$ \\
\hline & & $88 / 89$ & 371 & $208(56.0)$ & 97.95 & $2.12(1.82-2.47)$ \\
\hline & & $96 / 97$ & 188 & $95(50.5)$ & 60.43 & $1.57(1.26-1.96)$ \\
\hline & \multirow{3}{*}{ Women } & $78 / 79$ & 1195 & $405(33.9)$ & 285.68 & $1.42(1.27-1.57)$ \\
\hline & & $88 / 89$ & 1554 & $701(45.1)$ & 472.31 & $1.48(1.37-1.61)$ \\
\hline & & $96 / 97$ & 749 & $342(45.7)$ & 245.99 & $1.39(1.24-1.55)$ \\
\hline \multirow{6}{*}{$5-10$ years } & \multirow{3}{*}{ Men } & $78 / 79$ & 162 & $83(51.2)$ & 54.17 & $1.53(1.14-2 . .04)$ \\
\hline & & $88 / 89$ & 163 & $88(54.0)$ & 54.77 & $1.61(1.25-2 . .06)$ \\
\hline & & 96/97 & 93 & $58(62.3)$ & 33.56 & $1.73(1.32-2.26)$ \\
\hline & \multirow{3}{*}{ Women } & $78 / 79$ & 790 & $366(46.3)$ & 255.16 & $1.43(1.28-1.60)$ \\
\hline & & $88 / 89$ & 853 & $455(53.3)$ & 318.87 & $1.42(1.29-1.58)$ \\
\hline & & 96/97 & 407 & $258(63.3)$ & 146.69 & $1.76(1.54-2.02)$ \\
\hline
\end{tabular}


Table 3 Standardized mortality rates in given time intervals with respect to age group and cohort (both sexes)

\begin{tabular}{|c|c|c|c|c|c|c|}
\hline Follow up time & Age-group, years & Cohort & $\mathrm{n}$ & Dead, n (\%) & Expected dead, $\mathrm{n}$ & SMR $(95 \% \mathrm{Cl})$ \\
\hline \multirow[t]{12}{*}{$0-6$ months } & $50-64$ & & & & & \\
\hline & & $78 / 79$ & 254 & $7(2.7)$ & 1.3 & $5.25(1.62-9.57)$ \\
\hline & & $88 / 89$ & 170 & $10(5.9)$ & 1.0 & $10.54(4.53-17.86)$ \\
\hline & & $96 / 97$ & 60 & $4(6.7)$ & 0.2 & $17.19(3.66-37.53)$ \\
\hline & $65-84$ & & & & & \\
\hline & & $78 / 79$ & 1322 & $223(16.9)$ & 35.2 & $6.33(5.49-7.20)$ \\
\hline & & $88 / 89$ & 1606 & $257(16.0)$ & 40.9 & $6.29(5.49-7.15)$ \\
\hline & & $96 / 97$ & 719 & $107(14.9)$ & 17.8 & $6.03(4.88-7.28)$ \\
\hline & $\geq 85$ & & & & & \\
\hline & & $78 / 79$ & 361 & $124(34.3)$ & 27.6 & $4.49(3.67-5.38)$ \\
\hline & & $88 / 89$ & 843 & $241(28.6)$ & 70.8 & $3.40(2.94-3.90)$ \\
\hline & & $96 / 97$ & 475 & $117(24.6)$ & 39.4 & $2.97(2.43-3.60)$ \\
\hline \multirow[t]{12}{*}{ 6-12 months } & $50-64$ & & & & & \\
\hline & & $78 / 79$ & 247 & $4(1.3)$ & 1.33 & $2.99(0.68-16.25)$ \\
\hline & & $88 / 89$ & 160 & $3(1.9)$ & 0.90 & $3.35(0.00-7.86)$ \\
\hline & & $96 / 97$ & 56 & $1(1.8)$ & 0.22 & $4.54(0.00-16.35)$ \\
\hline & $65-84$ & & & & & \\
\hline & & $78 / 79$ & 1099 & $64(30.1)$ & 30.14 & $2.12(1.62-2.67)$ \\
\hline & & $88 / 89$ & 1349 & $102(7.6)$ & 36.64 & $2.78(2.26-3.33)$ \\
\hline & & $96 / 97$ & 612 & $39(6.4)$ & 16.03 & $2.43(1.70-3.24)$ \\
\hline & $\geq 85$ & & & & & \\
\hline & & $78 / 79$ & 237 & $29(12.2)$ & 22.39 & $1.30(0.85-1.81)$ \\
\hline & & $88 / 89$ & 602 & $81(13.5)$ & 56.68 & $1.43(1.13-1.76)$ \\
\hline & & $96 / 97$ & 358 & 49 (13.7) & 32.97 & $1.49(1.09-1.93)$ \\
\hline \multirow[t]{12}{*}{$1-5$ years } & $50-64$ & & & & & \\
\hline & & 78/79 & 243 & $31(12.8)$ & 11.79 & $2.63(1.75-3.59)$ \\
\hline & & $88 / 89$ & 157 & $28(17.8)$ & 7.41 & $3.78(2.46-5.31)$ \\
\hline & & $96 / 97$ & 55 & $7(12.7)$ & 2.03 & $3.45(1.12-6.47)$ \\
\hline & $65-84$ & & & & & \\
\hline & & $78 / 79$ & 1035 & $363(35.1)$ & 224.54 & $1.62(1.45-1.80)$ \\
\hline & & $88 / 89$ & 1247 & $533(42.7)$ & 260.07 & $2.05(1.87-2.24)$ \\
\hline & & $96 / 97$ & 573 & $226(39.4)$ & 120.21 & $1.88(1.64-2.15)$ \\
\hline & $\geq 85$ & & & & & \\
\hline & & $78 / 79$ & 208 & $140(0.67)$ & 121.25 & $1.36(0.97-1.37)$ \\
\hline & & $88 / 89$ & 521 & $348(66.8)$ & 302.79 & $1.15(1.03-1.28)$ \\
\hline & & $96 / 97$ & 309 & $204(66.0)$ & 184.18 & $1.11(0.97-1.27)$ \\
\hline \multirow[t]{8}{*}{$5-10$ years } & $50-64$ & & & & & \\
\hline & & $78 / 79$ & 212 & $36(17.0)$ & 17.94 & $2.01(1.38-2.74)$ \\
\hline & & $88 / 89$ & 129 & $28(21.7)$ & 9.99 & $2.80(1.81-3.93)$ \\
\hline & & 96/97 & 48 & $10(20.8)$ & 2.91 & $3.44(1.51-5.91)$ \\
\hline & $65-84$ & & & & & \\
\hline & & 78/79 & 672 & $359(53.4)$ & 233.11 & $1.54(1.38-1.72)$ \\
\hline & & $88 / 89$ & 714 & $363(50.8)$ & 233.4 & $1.55(1.40-1.73)$ \\
\hline & & 96/97 & 347 & $213(61.4)$ & 106.23 & $2.01(1.74-2.31)$ \\
\hline
\end{tabular}


Table 3 Standardized mortality rates in given time intervals with respect to age group and cohort (both sexes) (Continued)

\begin{tabular}{|c|c|c|c|c|}
\hline $78 / 79$ & 68 & $54(79.4)$ & 58.29 & $0.93(0.66-1.32)$ \\
\hline $88 / 89$ & 173 & $152(87.9)$ & 130.22 & $1.17(0.98-1.38)$ \\
\hline 96/97 & 105 & 93 (88.6) & 71.11 & $1.31(1.07-1.61)$ \\
\hline
\end{tabular}

among female hip fracture patients aged $\geq 85$ years. In other age groups, no statistically significant changes were seen. The duration of excess mortality ranged from 2 years in men aged $\geq 85$ years to more than 10 years in women aged $65-84$ years.

\section{Excess mortality}

The observed 1-year SMRs in the present study tended to be higher than in other similar reports. One study on hip fracture caused by falls from standing height or less in patients aged > 60 years showed a 1-year SMR of

Table 4 Standardized mortality rates in given time intervals with respect to fracture type and cohort (both sexes)

\begin{tabular}{|c|c|c|c|c|c|c|}
\hline Follow up time & Fracture type & Cohort & $\mathrm{n}$ & Dead, n (\%) & Expected dead, $\mathrm{n}$ & SMR $(95 \% \mathrm{CI})$ \\
\hline \multirow[t]{8}{*}{$0-6$ months } & Femoral neck & & & & & \\
\hline & & $78 / 79$ & 1185 & $203(17.1)$ & 36.7 & $5.53(4.76-6.37)$ \\
\hline & & $88 / 89$ & 1534 & $263(17.1)$ & 62.6 & $4.20(3.66-4.76)$ \\
\hline & & $96 / 97$ & 691 & $127(18.4)$ & 30.2 & $4.21(3.44-5.05)$ \\
\hline & Inter-trochanteric & & & & & \\
\hline & & $78 / 79$ & 751 & $151(20.1)$ & 27.4 & $5.51(4.61-6.52)$ \\
\hline & & $88 / 89$ & 1085 & $245(22.6)$ & 50.0 & $4.90(4.23-5.63)$ \\
\hline & & $96 / 97$ & 563 & $101(17.9)$ & 27.2 & $3.71(2.95-4.56)$ \\
\hline \multirow[t]{8}{*}{ 6-12 months } & Femoral neck & & & & & \\
\hline & & $78 / 79$ & 982 & $61(6.2)$ & 30.55 & $2.00(1.50-2 . .52)$ \\
\hline & & $88 / 89$ & 1271 & $105(8.3)$ & 51.89 & $2.02(1.64-2.43)$ \\
\hline & & $96 / 97$ & 564 & $46(8.2)$ & 25.53 & $1.80(1.30-2.36)$ \\
\hline & Inter-trochanteric & & & & & \\
\hline & & $78 / 79$ & 600 & $36(6.0)$ & 23.31 & $1.54(1.05-2.10)$ \\
\hline & & $88 / 89$ & 840 & $81(9.6)$ & 42.33 & $1.91(1.51-2.36)$ \\
\hline & & $96 / 97$ & 462 & $43(9.3)$ & 23.69 & $1.82(1.29-2.41)$ \\
\hline \multirow[t]{8}{*}{$1-5$ years } & Femoral neck & & & & & \\
\hline & & $78 / 79$ & 921 & $312(33.9)$ & 205.26 & $1.52(1.32-1.71)$ \\
\hline & & $88 / 89$ & 1166 & $527(45.2)$ & 325.74 & $1.62(1.47-1.77)$ \\
\hline & & $96 / 97$ & 518 & $224(43.2)$ & 161.04 & $1.39(1.21-1.60)$ \\
\hline & Inter-trochanteric & & & & & \\
\hline & & $78 / 79$ & 564 & $221(39.2)$ & 152.31 & $1.45(1.25-1.67)$ \\
\hline & & $88 / 89$ & 759 & $382(50.3)$ & 244.52 & $1.56(1.39-1.75)$ \\
\hline & & $96 / 97$ & 419 & $213(50.8)$ & 145.39 & $1.47(1.27-1.69)$ \\
\hline \multirow[t]{8}{*}{$5-10$ years } & Femoral neck & & & & & \\
\hline & & 78/79 & 609 & $260(42.7)$ & 191.54 & $1.36(1.19-1.54)$ \\
\hline & & $88 / 89$ & 639 & $322(50.4)$ & 229.64 & $1.40(1.25-1.57)$ \\
\hline & & $96 / 97$ & 294 & $176(59.9)$ & 99.77 & $1.76(1.52-2.07)$ \\
\hline & Inter-trochanteric & & & & & \\
\hline & & $78 / 79$ & 343 & $189(55.1)$ & 117.78 & $1.60(1.35-1.90)$ \\
\hline & & $88 / 89$ & 377 & $221(58.6)$ & 144.01 & $1.53(1.32-1.79)$ \\
\hline & & 96/97 & 206 & $140(68.0)$ & 80.48 & $1.74(1.45-2.10)$ \\
\hline
\end{tabular}


Table 5 Standardized mortality rates for the 0-1 year interval after fracture with respect to sex and cohort

\begin{tabular}{|c|c|c|c|c|c|c|}
\hline & Age-group, years & Cohort & $\mathrm{n}$ & Dead, n (\%) & Expected dead, $n$ & SMR $(95 \% \mathrm{Cl})$ \\
\hline \multirow[t]{12}{*}{ Men } & $50-64$ & & & & & \\
\hline & & $78 / 79$ & 74 & $3(4.1)$ & 1.26 & $2.38(0.00-5.58)$ \\
\hline & & $88 / 89$ & 63 & $5(7.9)$ & 0.99 & $5.05(1.02-10.42)$ \\
\hline & & $96 / 97$ & 22 & $2(9.1)$ & 0.23 & $8.76(0.00-26.70)$ \\
\hline & $65-84$ & & & & & \\
\hline & & $78 / 79$ & 281 & $93(33.1)$ & 17.13 & $5.43(4.30-6.74)$ \\
\hline & & $88 / 89$ & 363 & $117(32.2)$ & 22.19 & $5.27(4.27-6.41)$ \\
\hline & & $96 / 97$ & 170 & $43(25.3)$ & 10.92 & $3.94(2.76-5.29)$ \\
\hline & $\geq 85$ & & & & & \\
\hline & & $78 / 79$ & 62 & $30(48.4)$ & 3.18 & $3.18(2.00-4.93)$ \\
\hline & & $88 / 89$ & 120 & $53(44.2)$ & 2.85 & $2.85(2.07-3.84)$ \\
\hline & & $96 / 97$ & 87 & $46(52.9)$ & 3.31 & $3.31(2.30-4.70)$ \\
\hline \multirow[t]{12}{*}{ Women } & $50-64$ & & & & & \\
\hline & & $78 / 79$ & 180 & $8(4.4)$ & 1.41 & $5.67(2.10-10.02)$ \\
\hline & & $88 / 89$ & 107 & $8(7.5)$ & 0.85 & $9.36(3.42-16.76)$ \\
\hline & & $96 / 97$ & 38 & $3(7.9)$ & 0.22 & $13.37(0.00-32.24)$ \\
\hline & $65-84$ & & & & & \\
\hline & & $78 / 79$ & 1041 & 194 (18.6) & 48.22 & $4.02(3.45-4.64)$ \\
\hline & & $88 / 89$ & 1243 & $242(19.5)$ & 55.33 & $4.37(3.82-4.97)$ \\
\hline & & $96 / 97$ & 549 & $103(18.8)$ & 22.86 & $4.51(3.62-5.48)$ \\
\hline & $\geq 85$ & & & & & \\
\hline & & $78 / 79$ & 299 & $123(41.1)$ & 40.56 & $3.03(2.46-3.68)$ \\
\hline & & $88 / 89$ & 723 & $269(37.2)$ & 108.90 & $2.47(2.16-2.82)$ \\
\hline & & $96 / 97$ & 388 & $120(30.9)$ & 58.47 & $2.05(1.69-2.46)$ \\
\hline
\end{tabular}

2.18 for women and 3.17 for men [22]. Another study only including cognitively intact, ambulatory patients aged $\geq 65$ years reported an overall 1-year SMR of 1.5 [8]. The present study includes practically all hip fracture patients aged $>50$ years in Oslo, including those living in nursing homes. Holvik et al. reported a one-year mortality of $46 \%$ in patients admitted from nursing homes, compared with $13.7 \%$ in patients living at home at the time of fracture [23]. In the present study, place of living is not registered in all three cohorts. However, in the 1988-89 cohort, $24 \%$ of the patients stayed in nursing home at the time of the fracture. Thus, the higher mortality among nursing home residents may have contributed to the high SMR in the current study. By also including those aged 50-65 years, average SMR is expected to increase because of the high relative excess mortality in this age group.

\section{Excess mortality according to age}

The higher relative excess mortality among the youngest compared with the oldest is in accordance with other reports $[5,7,24]$. The high impact of hip fracture on relative excess mortality among the youngest is probably related to the low mortality in the corresponding population, and the higher frequency of comorbidity in young hip fracture patients compared with the background population with same age $[6,18,25,26]$.

\section{Excess mortality according to sex}

As in other reports, we found a higher excess mortality in men compared with women $[5,8,10,27]$. Higher excess mortality in men is also reported in studies adjusting for the higher rates of complications and comorbidity $[6,10]$. The reasons for the higher excess mortality in men remain unclear.

\section{Excess mortality according to time after fracture}

The highest excess mortality occurred within the first six months after the fracture, in accordance with earlier reports $[5,6,11]$. The high mortality in this period is probably a combined effect of the trauma and comorbidity $[6,11]$. The lower SMR during long-term follow up is to be expected, as the impact of trauma declines with time.

\section{Secular changes of excess mortality}

Earlier reports on changes in mortality over the decades have been conflicting. A population-based British study 
Table 6 Duration of excess mortality according to sex, age-group, and cohort

\begin{tabular}{|c|c|c|c|c|}
\hline Sex & $\begin{array}{l}\text { Age-group, } \\
\text { years }\end{array}$ & Cohort & Included, n & $\begin{array}{c}\text { Duration of excess } \\
\text { mortality, years }\end{array}$ \\
\hline \multicolumn{5}{|l|}{ Men } \\
\hline & \multirow[t]{3}{*}{$50-64$} & 78/79 & 74 & 6 \\
\hline & & $88 / 89$ & 63 & 9 \\
\hline & & $96 / 97$ & 22 & 3 \\
\hline & \multirow[t]{3}{*}{$65-84$} & 78/79 & 281 & $15^{\text {a) }}$ \\
\hline & & $88 / 89$ & 363 & 11 \\
\hline & & $96 / 97$ & 170 & $>10^{b)}$ \\
\hline & \multirow[t]{3}{*}{$\geq 85$} & $78 / 79$ & 62 & 3 \\
\hline & & $88 / 89$ & 120 & 3 \\
\hline & & $96 / 97$ & 87 & 2 \\
\hline \multirow[t]{9}{*}{ Women } & \multirow[t]{3}{*}{$50-64$} & $78 / 79$ & 180 & 17 \\
\hline & & $88 / 89$ & 107 & 12 \\
\hline & & $96 / 97$ & 38 & 9 \\
\hline & \multirow[t]{3}{*}{$65-84$} & 78/79 & 1041 & $>19^{\text {a) }}$ \\
\hline & & $88 / 89$ & 1243 & 14 \\
\hline & & 96/97 & 549 & 10 \\
\hline & \multirow[t]{3}{*}{$\geq 85$} & $78 / 79$ & 299 & 3 \\
\hline & & $88 / 89$ & 723 & 7 \\
\hline & & $96 / 97$ & 388 & 8 \\
\hline
\end{tabular}

a) Further analysis not possible due to few patients left.

b) End of follow up at 10.7 years.

showed a reduction in one-year mortality from 1968 to 1983, but no reduction from 1983 to 1998 [13]. Furthermore, a Danish register study reported a slightly increased excess mortality in hip fracture patients in the period 1986 to 2001 compared with 1981 to 1985 [9]. The methods used in these studies differ from the present one, which limit the possibility for comparison of the results.

\section{Secular changes of excess mortality according to age}

The present data showed a statistically significant reduction in the 0-6 month SMR from 1978/79 to $1996 / 97$ in patients aged $\geq 85$ years. Decreased mortality following pneumonia and myocardial infarction [28-31], which are common concomitant diseases in old hip fracture patients [12], may have contributed to the improved survival in the oldest age group. One may speculate that an increasing disease burden in hip fracture patients aged $<85$ years, may be a reason for the stable SMR over time in these age groups. These speculations are supported by data from 2005 - 2009 from the Norwegian hip fracture register, which shows an increased proportion of patients with an ASA(American Society of Anaesthesiologists) score [32] of 3 (severe systemic disease) at admittance, and fewer with an ASA score of 1 and 2 (none or mild systemic disease) [33]. It is not known when this trend started.

\section{Secular changes of excess mortality according to sex}

Although more pronounced in women than in men, there was a similar reduction in the excess mortality for both sexes during the 0-6 months interval from 1978/79 to $1996 / 97$ in the analyses stratified on sex (Table 2). However, during the 6-12 months and the 1-5 years interval there was a trend towards increased SMR from $1978 / 79$ to $1988 / 89$ and a reduction from $1988 / 89$ to $1996 / 97$ in men, which was not found in women. The present data do not provide any explanation for this. Changes in incidence of, and survival after diseases more common in men than in women might have influenced the outcome in men $[28,34]$. Furthermore, Bacon et al. found a greater improvement of survival in elderly men than in women in the period 1965 to 1993 [35]. This highlights the need for separate analyses of mortality in men and women.

\section{Secular changes of excess mortality according to time after fracture}

The present data show that secular changes in SMR are most pronounced during short time follow up. This is to be expected, as the excess mortality is highest in the early phase after the fracture. Modifiable factors which could improve survival are time from fracture to operation [36], the use of prophylactic antibiotics [37], and early mobilisation [38].

\section{Secular changes of excess mortality according to fracture type}

Patients suffering from intertrochanteric fractures are supposed to be frailer and have more comorbidity and a higher mortality than those with femoral neck fractures [39], and the increased proportion of intertrochanteric fractures in our study could have influenced the results. However, in the present study, the SMRs were similar for the two fracture types, implying that fracture type is not a major determinant of excess mortality. The results are in concordance with other studies that have shown that the age- adjusted mortality in patients with intertrochanteric fractures is the same as for those with femoral neck fractures $[40,41]$.

\section{Secular changes of duration of excess mortality}

Duration of the period with excess mortality ranged from two years to more than 19 years in the different sex- and age-groups. Hip fracture patients aged 65-84 years had, in accordance with other population based studies [5,11], the longest duration of excess mortality. This prolonged period of excess mortality may reflect the high rate of comorbid conditions also among those surviving the first 
months after the fracture. This is further emphasised in other studies reporting prolonged excess mortality only in patients with a high degree of comorbidity [6,11]. It is to expect that the oldest patients have the shortest period of excess mortality, as a high proportion in this age group will die during the follow up. However, the present study demonstrated an increase from 3 to 8 years of the period with excess mortality among the oldest women. Expected remaining life-time in Norwegian women aged 85 years was 5.9 years in 1996 according to the data provided from Statistics Norway, and changes in duration of excess mortality are therefore considered to be of clinical relevance. The increased duration of excess mortality may be a result of the reduced 6-months and 1-year excess mortality observed in hip fracture patients $\geq 85$ years, which may have left a higher number of frail and sick patients for the long term follow up, contributing to excess mortality for a longer time period. Contrary, the shorter duration of excess mortality in men compared with women, may reflect the higher early mortality in men, leaving few and relatively healthy subjects for follow up.

\section{Limitations}

Although, SMRs allow comparison of mortality in cohorts from populations with different background mortality, it may be considered as a limitation that no data on comorbidity or medication were available. Hip fracture patients are likely to have a higher frequency of comorbidity than the general population $[6,11,18,25]$, and changes in disease burden and medication in the fracture population may have differed from that in the background population. Another limitation of the study is that data were collected for only one calendar year in 1996/97, influencing the statistical power, particularly in men and the younger patients.

The strengths of the present study are the completeness of registrations of deaths and the long follow up of hip fracture patients from validated population-based incidence studies over three decades. No major changes in diagnostics took place in the actual period. The definitions remained the same, and the data collection was equal in the three incidence studies [14-16]. No electronic diagnosis registers were available in 1978/79. However, the additional identification of the hip fractures through medical records and $\mathrm{x}$-rays in all three incidence studies makes the data collection accurate and comparable in all three studies [14].

\section{Conclusion}

To conclude, hip fracture patients have a considerably higher mortality than the background population with same age and gender. Over the decades, a statistically significant reduction of one year excess mortality was only seen in the oldest women, suggesting that specific efforts intending to improve prevention and treatment of osteoporosis and osteoporotic fractures in the youngest elderly are required. Mortality studies including more recent data with a higher proportion of patients treated with bisphosphonates and hip replacement are warranted.

\section{Additional file}

\section{Additional file 1: Excluded patients. Flow chart illustrating exclusion} of patients who were included in the original incidence studies.

\section{Abbreviations}

SMR: Standardized mortality ratio; Cl: Confidence interval.

\section{Competing interests}

None of the authors have any financial or non-financial competing interest to declare.

\section{Authors' contribution}

TEF contributed to acquisition of data and design of the study, performed statistical analysis and interpretation of data, and wrote the manuscript. HEM participated in interpretation of data and revising of the manuscript. JAF contributed to acquisition and interpretation of data and revising of the manuscript. AWM contributed to acquisition of data and revising of the manuscript. TWL participated in the design of the study and performed statistical analysis, and helped to draft parts of the manuscript. CML contributed to acquisition and interpretation of data, conception and design, and drafting and revising of the manuscript. All authors read and approved the final manuscript.

\section{Author details}

1Department of Internal Medicine, Innlandet Hospital Trust, Skolegata 32, Hamar N-2318, Norway. ${ }^{2}$ Faculty of Medicine, University of Oslo, Klaus Torgårds vei 3, Oslo N-0372, Norway. ${ }^{3}$ Division of Epidemiology, Norwegian Institute of Public Health, Marcus Thranes gate 6, Oslo N-0473, Norway. ${ }^{4}$ Department of Community Medicine, Faculty of Medicine, University of Oslo, Kirkeveien 166, Oslo 0450, Norway. ${ }^{5}$ Department of Medicine, Oslo University Hospital, Kirkeveien 166, Oslo N-0450, Norway. ${ }^{6}$ Biostatistics and Epidemiology Unit, Oslo University Hospital, Kirkeveien 166, Oslo N-0450, Norway. ${ }^{7}$ Centre for Child and Adolescent Mental Health, Eastern and Southern Norway, Gullhaug Torg 4B, Oslo N-0484, Norway. ${ }^{8}$ Norwegian Centre for Violence and Traumatic Stress Studies, Kirkeveien 166, house no 48, Oslo N-0450, Norway.

Received: 25 September 2012 Accepted: 5 March 2013

Published: 13 March 2013

\section{References}

1. Abrahamsen B, Van ST, Ariely R, Olson M, Cooper C: Excess mortality following hip fracture: a systematic epidemiological review. Osteoporos Int 2009, 20:1633-1650.

2. Robbins JA, Biggs ML, Cauley J: Adjusted mortality after hip fracture: from the cardiovascular health study. J Am Geriatr Soc 2006, 54:1885-1891.

3. Johnell O, Kanis JA: An estimate of the worldwide prevalence, mortality and disability associated with hip fracture. Osteoporos Int 2004, 15:897-902.

4. Fitts WT Jr, Lehr HB, Schor S, Roberts B: Life expectancy after fracture of the hip. Surg Gynecol Obstet 1959, 108:7-12.

5. Forsen L, Sogaard AJ, Meyer HE, Edna T, Kopjar B: Survival after hip fracture: short- and long-term excess mortality according to age and gender. Osteoporos Int 1999, 10:73-78.

6. Meyer HE, Tverdal A, Falch JA, Pedersen Jl: Factors associated with mortality after hip fracture. Osteoporos Int 2000, 11:228-232.

7. Johnston AT, Barnsdale L, Smith R, Duncan K, Hutchison JD: Change in long-term mortality associated with fractures of the hip: evidence from the Scottish hip fracture audit. J Bone Joint Surg Br 2010, 92:989-993. 
8. Paksima N, Koval KJ, Aharanoff G, Walsh M, Kubiak EN, Zuckerman JD, et al: Predictors of mortality after hip fracture: a 10-year prospective study. Bull NYU Hosp Jt Dis 2008, 66:111-117.

9. Vestergaard $P$, Rejnmark L, Mosekilde L: Has mortality after a hip fracture increased? J Am Geriatr Soc 2007, 55:1720-1726.

10. Kannegaard PN, der MS V, Eiken P, Abrahamsen B: Excess mortality in men compared with women following a hip fracture. National analysis of comedications, comorbidity and survival. Age Ageing 2010, 39:203-209.

11. Tosteson AN, Gottlieb DJ, Radley DC, Fisher ES, Melton LJ III: Excess mortality following hip fracture: the role of underlying health status. Osteoporos Int 2007, 18:1463-1472.

12. Roche JJ, Wenn RT, Sahota O, Moran CG: Effect of comorbidities and postoperative complications on mortality after hip fracture in elderly people: prospective observational cohort study. BMJ 2005, 331:1374.

13. Roberts SE, Goldacre MJ: Time trends and demography of mortality after fractured neck of femur in an English population, 1968-98: database study. BMJ 2003, 327:771-775.

14. Lofthus CM, Osnes EK, Falch JA, Kaastad TS, Kristiansen IS, Nordsletten L, et al: Epidemiology of hip fractures in Oslo, Norway. Bone 2001, 29:413-418.

15. Falch JA, Kaastad TS, Bohler G, Espeland J, Sundsvold OJ: Secular increase and geographical differences in hip fracture incidence in Norway. Bone 1993, 14:643-645.

16. Falch JA, llebekk A, Slungaard U: Epidemiology of hip fractures in Norway. Acta Orthop Scand 1985, 56:12-16.

17. Zetterberg $\mathrm{CH}$, Irstam L, Andersson GB: Femoral neck fractures in young adults. Acta Orthop Scand 1982, 53:427-435

18. Lofthus CM, Osnes EK, Meyer HE, Kristiansen IS, Nordsletten L, Falch JA: Young patients with hip fracture: a population-based study of bone mass and risk factors for osteoporosis. Osteoporos Int 2006, 17:1666-1672.

19. Therneau T, Offord J: Expected Survival Based on Hazard Rates (Update). Section of Biostatistics, Mayo Clinic 1999, 18:2.

20. Andersen PK, Vaeth M: Simple parametric and nonparametric models for excess and relative mortality. Biometrics 1989, 45:523-535.

21. Efron B, Tibshirani R: An Introduction to the Bootstrap. Boca Raton, FL: Chapman \& Hall/CRC; 1993.

22. Center JR, Nguyen TV, Schneider D, Sambrook PN, Eisman JA: Mortality after all major types of osteoporotic fracture in men and women: an observational study. Lancet 1999, 353:878-882.

23. Holvik K, Ranhoff AH, Martinsen MI, Solheim LF: Predictors of mortality in older hip fracture inpatients admitted to an orthogeriatric unit in Oslo, Norway. J Aging Health 2010, 2:1114-1131.

24. Richmond J, Aharonoff GB, Zuckerman JD, Koval KJ: Mortality risk after hip fracture. J Orthop Trauma 2003, 17:53-56.

25. Vestergaard P, Rejnmark L, Mosekilde L: Increased mortality in patients with a hip fracture-effect of pre-morbid conditions and post-fracture complications. Osteoporos Int 2007, 18:1583-1593.

26. Holt G, Smith R, Duncan K, Hutchison JD, Gregori A: Epidemiology and outcome after hip fracture in the under 65 s-evidence from the Scottish Hip Fracture Audit. Injury 2008, 39:1175-1181.

27. Piirtola M, Vahlberg T, Lopponen M, Raiha I, Isoaho R, Kivela SL: Fractures as predictors of excess mortality in the aged-a population-based study with a 12-year follow-up. Eur J Epidemiol 2008, 23:747-755.

28. Molstad P: Coronary heart disease in women: less extensive disease and improved long-term survival compared to men. Scand Cardiovasc J 2009, 43:10-16.

29. Wilhelmsen L, Rosengren A, Johansson S, Lappas G: Coronary heart disease attack rate, incidence and mortality 1975-1994 in Goteborg, Sweden. Eur Heart J 1997, 18:572-581.

30. McGovern PG, Jacobs DR Jr, Shahar E, Arnett DK, Folsom AR, Blackburn $H_{1}$ et al: Trends in acute coronary heart disease mortality, morbidity, and medical care from 1985 through 1997: the Minnesota heart survey. Circulation 2001, 104:19-24

31. Ruhnke GW, Coca-Perraillon M, Kitch BT, Cutler DM: Marked reduction in 30-day mortality among elderly patients with community-acquired pneumonia. Am J Med 2011, 124:171-178.

32. Saklad M: Grading of Patients for Surgical Procedures. Anesthesiology 1941, 3:281-284.

33. The Norwegian arthroplasty register (2010), Annual report 2010: Norwegian hip fracture register. 2010:108. cited 12 A.D. Jul 4. http://nrlweb.ihelse.net/ eng/Report_2010.pdf.
34. Panula J, Pihlajamaki H, Mattila VM, Jaatinen P, Vahlberg T, Aarnio P, et al: Mortality and cause of death in hip fracture patients aged 65 or older: a population-based study. BMC Musculoskelet Disord 2011, 12:105.

35. Bacon WE: Secular trends in hip fracture occurrence and survival: age and sex differences. J Aging Health 1996, 8:538-553.

36. Zuckerman JD, Skovron ML, Koval KJ, Aharonoff G, Frankel VH: Postoperative complications and mortality associated with operative delay in older patients who have a fracture of the hip. J Bone Joint Surg Am 1995, 77:1551-1556.

37. Gillespie WJ, Walenkamp G: Antibiotic prophylaxis for surgery for proximal femoral and other closed long bone fractures. Cochrane Database Syst Rev 2000, 2:CD000244.

38. Siu AL, Penrod JD, Boockvar KS, Koval K, Strauss E, Morrison RS: Early ambulation after hip fracture: effects on function and mortality. Arch Intern Med 2006, 10:166. 766-71.

39. Cornwall R, Gilbert MS, Koval KJ, Strauss E, Siu AL: Functional outcomes and mortality vary among different types of hip fractures: a function of patient characteristics. Clin Orthop Relat Res 2004, 425:64-71.

40. Kesmezacar H, Ayhan E, Unlu MC, Seker A, Karaca S: Predictors of mortality in elderly patients with an intertrochanteric or a femoral neck fracture. J Trauma 2010, 68:153-158.

41. Butler M, Forte ML, Joglekar SB, Swiontkowski MF, Kane RL: Evidence summary: systematic review of surgical treatments for geriatric hip fractures. J Bone Joint Surg Am 2011, 93:1104-1115.

doi:10.1186/1471-2318-13-25

Cite this article as: Finnes et al:: Secular reduction of excess mortality in hip fracture patients >85 years. BMC Geriatrics 2013 13:25.

\section{Submit your next manuscript to BioMed Central and take full advantage of:}

- Convenient online submission

- Thorough peer review

- No space constraints or color figure charges

- Immediate publication on acceptance

- Inclusion in PubMed, CAS, Scopus and Google Scholar

- Research which is freely available for redistribution 